\title{
Antibacterial Activity of Some Herbal Extracts for the Treatment of Typhoid Fever Sold in Okitipupa Town, Ondo State, Nigeria
}

\author{
*Adeyemo I.A.@1, Omolade C. $0^{2}$. \\ ${ }^{1}$ Department of Microbiology, Olusegun Agagu University of Science and Technology, Okitipupa, \\ Ondo State, \\ ${ }^{2}$ Department of Environmental Health Science, Faculty of Public Health, University of Ibadan, Oyo \\ State, Nigeria. \\ ${ }^{*} \mathrm{E}$ - mail of corresponding author: adeyemiyourfriend@gmail.com; 08035671847
}

Abstract
The study investigated and compared the antimicrobial potency of aqueous (cold and hot) and
ethanolic extracts of six plant parts used as herbal mixture against clinical isolate of Salmonella
typhi in Okitipupa town. Extracts from six plant parts used as herbal mixture were tested for
antibacterial activity against Salmonella typhi isolated from patients suffering from typhoid
fever. The antibacterial activities of each of the extracts (ethanolic, cold and hot waters) were
determined using agar diffusion method and the activities produced zone of inhibition ranging
from $20 \mathrm{~mm}$-34mm. Ethanolic extract was found to be more potent being capable of exerting
significant inhibitory activity on the test organism investigated with an inhibition zone of 34mm
followed by the cold-water extract (28mm) while hot water extract gave the least (20mm). The
phytochemical analysis showed the presence of saponins, tannins, flavonoids, phenols,
glucosinolates and triterpenes in the extracts but total absence of proteins. The study confirms
the medicinal value of herbal mixtures and justifies the claim of its local use in health remedies
for typhoid fever caused by Salmonella typhi. There is the need therefore to develop effective
combination of antimicrobial agents in purified form from higher plants and their parts for
clinical trials.
Keywords: Herbal mixture, antibacterial activity, typhoid fever, phytochemical analysis.

INTRODUCTION

Herbal medicine, also called phytomedicine or botanical medicines refers to the use of any plant's part: seeds, roots, leaves, barks, flowers, fruits etc. for medicinal purposes (Chaing et.al 1994). Herbal medicinal products (HMPs) are becoming increasingly popular (Briskin, 2000). Medicine, in several developing countries, using local traditions and belief, is still mainstay of healthcare (WHO, 2002; Willcox and Bodeker2004). Plants with medicinal properties have been used for centuries in the traditional system of medicines by humans for the treatment of diseases where they are considered to be effective and nontoxic (WHO, 2013). They have a vast potential but are only partly explored by modern methods (Mulugeta et al., 2021, Okunlola et.al, 2007). An estimated $80 \%$ of the world population still depends on traditional herbal medicines for their health security (Reddy et. al., 2021; WHO, 2002). In most African countries, herbal medicine is recognized as an important component of health care system especially among rural dwellers that constitutes about $70 \%$ of the population (Esimone et al., 2007). In Nigeria, there appears to be an overwhelming increase in the public awareness of the usage of herbal medicinal products in the treatment and/or prevention of diseases.

This may not be unconnected with the active mass media advertisement embarked upon by the producers and marketers of the herbal medicinal products who have taken the advantage of the relatively high cost of the conventional pharmaceutical dosage forms, inaccessibility of the orthodox medical services to a vast majority of people particularly in the rural areas and the reservations by the public due to prevalence of fake, substandard or counterfeit drugs in the market. These have placed the herbal medicinal products as a ready alternative to conventional dosage forms in the treatment of diseases. With this increased usage, the safety, efficacy and quality of these medicines have been an important concern for health authorities and health professionals (Adeleye, et al., 2005). 
Herbal preparations are often perceived as being natural and therefore safe, but they are not free from adverse effects which may be due to factors such as adulteration, substitution, mis-identification, lack of standardization, incorrect preparations and contamination with pathogenic bacteria that present serious health hazards (Arias et al., 1999). Although the World Health Organization advocated for the integration of herbal medicinal products into the primary health care system of developing countries (WHO, 2013) safety issues related to herbal drugs continue to be ignored by the herbalist whose methods of concocting herbal preparations for the public are usually unhygienic with the attendant microbiological hazards (Esimone et al., 2007). Accordingly, gross microbial contaminations of herbal medicinal products commonly consumed in Nigeria have been severally demonstrated (Onawunmi and Lamikanra, 1987; Esimone et al., 2007). On one hand, such grossly contaminated herbal medicinal products may serve as potential sources of transmission of pathogenic organisms from products to consumers. Alternatively, it may result to product spoilage (Awosika et al., 1993).

\section{MATERIALS AND METHODS}

Sample Collection

All the different plant ingredients for the preparation of herbal mixture for typhoid fever were obtained from a herb seller in Okelloro street in Okitipupa town, Ondo state (Table 3). The ingredients were collected in a sterile container and taken to the laboratory for analysis. All analysis was carried out at Olusegun Agagu University of Science and Technology (OAUSTECH) Laboratory Okitipupa.

Preparation and Extraction of Plant

Ingredients

The collected ingredients were prepared by first breaking the backs into smaller pieces using a sterile mortar and pestle and milling the leaves using an electric blender. The plant materials were extracted with $300 \mathrm{ml}$ of $80 \%$ ethanol, ordinary distilled water and hot distilled water in which each was measured using a measuring cylinder and poured into sterile containers with proper labeling according to the names of the solvents. The mixtures were homogenized and kept for $24 \mathrm{hrs}$ at room temperature.

Each labeled mixture was then filtered using a sterile muslin bag after which the extract was obtained, the filtrate was further spinned in a centrifuge to obtain a clearer extract, hence it was kept in the refrigerator.

\section{Phytochemical Screening}

The extracts with different solvents were screened for the presence of some phytochemical compounds as described by Harborne (1998).

\section{Media Preparation}

MacConkey agar (49.53g) powder was suspended in $1000 \mathrm{ml}$ purified/distilled water and then boiled to dissolve the medium completely. The mixture was then Sterilized by autoclaving at $15 \mathrm{lbs}$ pressure $\left(121^{\circ} \mathrm{C}\right)$ for 15 minutes and cooled to $45-50^{\circ} \mathrm{C}$ before pouring into Petri plates.

Culturing of Test Organism (Salmonella Typhi) Blood samples positively tested for typhoid fever was collected from State Specialist Hospital Ondo, in an anticoagulant bottle and brought to the laboratory. A loopful of the sample was streaked onto the surface of prepared MacConkey agar plates. The plates were incubated at $37^{\circ} \mathrm{C}$ for $24 \mathrm{hrs}$. The media plates were then examined for growth. Pure cultures were obtained by sub-culturing from a typical and well isolated colony on MacConkey agar. Identification of Salmonella typhi was done by gram staining technique and biochemical tests. A distinct colony was further picked from the plate and inoculated on a slant, incubated at $37^{\circ} \mathrm{C}$ for $24 \mathrm{hrs}$, kept in the refrigerator for further research purposes.

Susceptibility of Bacteria to Plant Extracts Susceptibility of the test isolate to the plant extracts was determined using agar well diffusion method described by Mbata and Saikia (2005). $2 \mathrm{ml}$ of overnight broth culture of salmonella typhi was taken and aseptically transferred into labeled sterile petri dishes. Then $15 \mathrm{ml}$ of molten sterile nutrient agar was poured into the seeded petri dishes and swirled to distribute the medium homogenously. After solidification, holes were made aseptically with a sterile cork borer and $0.1 \mathrm{ml}$ of each the extracts was introduced into the wells. The agents were allowed to diffuse into the medium and then incubated at $37^{\circ} \mathrm{C}$ for $24 \mathrm{hrs}$. One well containing water served as control in each plate. The plates were examined for zones of inhibition, which indicate the degree of susceptibility of the test organism which was measured with a meter rule and compared with the control well (containing water).

\section{RESULTS AND DISCUSSION}

Table 1 showed the plants and plant parts used in the preparation of the herbal mixture for this work. They are used in consortium to prepare the mixture. 
Table 1: Medicinal Plants and Parts used in trials for the Treatment of Typhoid Fever In Okitipupa Town, Ondo State, Nigeria

\begin{tabular}{lllll}
\hline Botanical names & Family & English names & Local names & Plant part used \\
\hline Carica papaya & Caricaceae & Pawpaw & Ibepe & Leaves \\
Cymbopogon citrates & Poaceae & Lemon grass & Ewe tea & Leaves \\
Enantia polycarpa & Annonaceae & & Osomolupa & Bark \\
Azadirachta indica & Meliaceae & Neem & Dongoyaro & Leaves \\
Rauvolfia vomitoria & Apocynaceae & Swizzle stick & Asofeyeje & Leaves \\
Mangifera indica & Anarcardiaceae & Mango & Mangoro & Matured bark and leaves \\
\hline
\end{tabular}

Phytochemical screening of the plant extracts revealed the presence of one or more of the following phytochemical components; tannin, saponin, phenols, flavonoids, glucosinolates, triterpenes and proteins as shown in Table 2. Ethanol, cold water and hot water extracts are all rich in phenols, tannins and glucosinolates but shows total absence of protein and amino acids. The presence of some phytochemicals in the plant extracts understudied is a function of their antimicrobial activities against the test pathogen as they play important roles in bioactivity of medicinal plants (Estrada et al., 2012). Phytochemicals exert antimicrobial activity through different mechanisms; tannins for example, act by iron deprivation, hydrogen binding or specific interactions with vital proteins such as enzymes in microbial cells (Akinpelu et al., 2008). Herbs that have tannins as their component are astringent in nature and are used for the treatment of gastrointestinal disorders such as diarrhea and dysentery, hence serves as remedy for typhoid fever. Saponin, which is responsible for numerous pharmacological properties (Estrada et al., 2012) was also tested positive in cold and ethanol extracts of the plant materials examined.

Alkaloid that has been associated with medicinal uses for centuries was found present in ethanol extract and absent in cold and hot extract of the plant materials. One of the most common biological properties of alkaloids is their toxicity against cells of foreign organisms (Akinpelu et al., 2008). Similarly, glucosinolates which was present in all the extracts of the plant materials used in this study, possess great inhibitory properties hence, the antimicrobial activity observed against the test pathogen.

Table 2: Result of Phytochemical Screening of the Higher Plants Used in the Research.

\begin{tabular}{llll}
\hline Phytochemical components & Cold water extract & Hot water extract & Ethanol extract \\
\hline Saponins & + & - & + \\
Phenols & + & + & + \\
Tannins & + & + & + \\
Flavonoids & - & - & + \\
Glucosinolates & + & + & + \\
Triterpenes and steroids & - & - & + \\
Protein and amino acids & - & - & - \\
\hline
\end{tabular}

Key: $+=$ Present- = Absent

Both aqueous and ethanolic extracts of the plant materials showed antimicrobial activity on the test inoculum as shown on Table 3. The sensitivity of the test organism to cold water, hot water and ethanolic extract of the plant materials were evaluated using the cup plate method. The highest susceptibility was recorded with the ethanolic extract with a zone of inhibition of $(34 \mathrm{~mm})$ followed by the cold water extract $(28 \mathrm{~mm})$, it was least susceptible to hot water extract $(20 \mathrm{~mm})$.

Table 3: Susceptibility of Test Organism to Plant Extracts at Different Concentrations

$\begin{array}{lllllll}\text { Plant extracts } & \text { Zone of inhibition }(\mathrm{mm}) & 1 \% & 2 \% & 3 \% & 4 \% & 5 \%\end{array}$

\begin{tabular}{|c|c|c|c|c|c|c|}
\hline Cold water extract & 28 & $15^{a}$ & $20^{b}$ & $22^{b}$ & $25^{\mathrm{bc}}$ & $28^{c}$ \\
\hline Hot water extract & 20 & $10^{\mathrm{a}}$ & $12^{\mathrm{a}}$ & $15^{\mathrm{ab}}$ & $18^{b}$ & $20^{\mathrm{b}}$ \\
\hline Ethanol extract & 34 & $20^{\mathrm{a}}$ & $22^{\mathrm{a}}$ & $24^{\mathrm{b}}$ & $28^{\mathrm{b}}$ & $34^{c}$ \\
\hline Control (distilled water) & No inhibition & 0 & 0 & 0 & 0 & 0 \\
\hline
\end{tabular}

abc ......Means on the same row with different superscripts are significantly different $(P<0.05)$.

Values are means of three replicate determinations. 
The study shows that all the plant extracts possess antimicrobial properties, with greater antimicrobial efficacy when used on Salmonella Typhi the causative agent of typhoid fever. It was clear from this study that solvent extraction affected the degree of antibacterial activity of the extracts this is in agreement with the work of Odikamnoro et al., (2015). There was progressive increase in zone of clearance as the concentration increases with the ethanolic extract having the highest zone of clearance at $5 \%(34 \mathrm{~mm})$ while the lowest at $1 \%$ was that of the hot water extract $(10 \mathrm{~mm})$. This could be due to the destructive effect of the hot water on some active components of the plants used. The ethanolic extract have the largest zone of clearance of the three because it is an organic solvent and will dissolve organic compounds better, hence the active component required for antimicrobial activity are better dissolved by ethanol than the cold water. The values of the zone of clearance differ significantly across the rows for all the extracts $(P<0.05)$ because as the concentrations increase across the rows, active ingredients that serves as antimicrobial agents also

\section{REFERENCES}

Adeleye, I. A., Okogi, G. and Ojo, E. O. (2005).Microbial contamination of herbal preparations in Lagos. Nigeria.Journal of Health, Population and Nutrition. 23 (3): 296-297.

Akinpelu D.A, Aiyegoro D. A. and Okoh A.I (2008). In Vitro antimicrobial and Phytochemical Properties of Crude extract of Stem bark of Afzeliaafricana (Smith). African Journal of Biotechnology.7(20): 3662-3667).

Arias, M. L., Chaves, C. and Alfaro, D. (1999). Microbiological analysis of some herbal infusions used as medicines. Rev Biomed. $\quad 10 \quad$ (1): $1-6$. http://www.imbiomed.com.max/uav.E nglish/ZYu91-01.html

Awosika, D. F. (1993).Local Medicinal Plants and Healthcare of Consumers.Clinical plants and healthcare of consumers.Clinical Pharmacy and Herbal Medicine. 9:28-31.

Briskin, D. (2000). Medicinal Plants and Phytomedicines.Linking Plant Biochemistry and Physiology to Human Health. Plant Physiology, 124(2), 507514. Retrieved March 27, 2021, from http://www.jstor.org/stable/4279453

Chaing HS, Merino-chavez G, Yang LL, Wang FN, Hafez ES (1994). Medicinal plants: becomes more available in the experimenting media. Generally, the present study has shown that all the plant materials tested possess a measure of antimicrobial properties and the antimicrobial potency is much greater when used synergistically against the test pathogen and is concentration dependent.

\section{CONCLUSION}

The plant materials examined in the present study have been successfully in use in Okitipupa Township in the Preparation of herbs for the treatment of typhoid fever caused by the test pathogen for centuries as attested by inhabitants of the township, particularly when modern drugs of choice failed in achieving the therapy. This study has confirmed the antibacterial potentials of the plant materials, thus supporting their folklore application as a medical remedy for typhoid fever. It is hoped that this study would lead to the discovery of some compounds that could be used to formulate new and more potent antimicrobial drugs of natural origin for the treatment of salmonella-infections particularly typhoid fever among others.

conception / contraception. Adv Contracept Deliv Syst.10(3-4):355-63. PMID: 12287843.

Esimone, C.O., Oleghe, P.O., Ibezim, E.C., Okeh, C. O. and Iroha, I. R. (2007). Susceptibility resistance profile of micro-organisms isolated from herbal medicine product. African J. Biotech. 6 (24): 2766-2775

Estrada-Castillón, E., Soto-Mata, B.E., GarzaLópez, M. et al.(2012). Medicinal plants in the southern region of the State of Nuevo León, México. J EthnobiologyEthnomedicine 8, 45 .https: // doi.org/10.1186/1746-4269-8$\underline{45}$

Harborne, J. B. Phytochemical methods - A Guide to Modern Technique of Plant analysis. Chapman and Hall, London. (1998).

Mbata T. and Saikia, A. (2005): Antibacterial Activity of Essential oil from Ocimumgratissimum on Listeria monocytogenes. Internet Journal of Food Safety V (7): 15-19

MulugetaTeshome, LegesseAdane andYinebeb Tariku (2021). Phytochemical Screening and Evaluation of Antibacterial Activities of Root Bark Extracts of Moringasteno petala. Research Journal of Medicinal Plants (15) : 1 - 6 
Odikamnoro OO, Uhuo CA, Ikeh IM, Ogiji ED, Ibiam GA, Azi SO, Akpam LJ and Okoh $\mathrm{NF}(2015)$. Antibacterial activities of two medicinal herbs on Salmonella typhi isolates in Abakaliki, Ebonyi State, Nigeria: Improvement to herbal medicine. Journal of Bacteriology research (7) 2: 14 - 18.

Okunlola, A., Adewoyin, A. B and Odeku, A. O. (2007). Evaluation of pharmaceutical and microbial qualities of some herbal medicinal products in South Western Nigeria.Tropical Journal of Pharmaceutical Research . 6(1): 661670.

Onawunmi, G. O. and Lamikanra, A. (1987).Microbial qualities of locally produced herbal preparations. Niger $\mathrm{J}$. Pharm .Sci 3: 56-63.

Reddy, Y. M.; Kumar, S. P.J.; Saritha, K. V.; Gopal, P.; Reddy, T. M.; SimalGandara, Jesus. (2021). "Phytochemical
Profiling of Methanolic fruit extract of Gardenia latifolia Ait. by LC-MS/MS Analysis and Evaluation of Its Antioxidant and Antimicrobial Activity" Plants 10(3): 545. https: //doi.org/10.3390/plants1003054 5

WHO (2002): Traditional medicine strategy 2002-2005. Geneva. https: / / www.who.int/medicines/public ations/traditional/trm_strategy14_23/e

WHO (2013): WHO traditional medicine strategy: 2014-2023. https://www.who.int/medicines/public ations/traditional/trm_strategy14_23/e $\underline{n} /$

Willcox $\overline{M L}$, Bodeker $\mathrm{G}$. Traditional herbal medicines for malaria.(2004). BMJ; 329(7475):1156-9.

https://doi:10.1136/bmj.329.7475.115 $\underline{6}$ 